\title{
Predictive Analysis of IoT Enabled Garden Soil Requirements using Web Services
}

\author{
K. Ojeswini Sesi Priya, P.V.S.S. Rashmika, K. Jamal, R. Indu Sree, T.N.S. Kruthika
}

\begin{abstract}
Smart gardening plays a key role in both supply and distribution of water to the plants. Plants play a key role in providing habitat and food for wild animals, human beings and regulate the water cycle. The important parameters for the quality and productivity of a plant growth are soil temperature, soil moisture, nutrients, humidity and Potential of Hydrogen $(\mathrm{PH})$. Soil moisture is the main factor which is most the effective reliable way to increase yielding. The main aim of the present research work, is to sense the essentials and fulfil the needs of the plants. For the real time practice there are five different garden zones such as Patio, Front yard, Back yard, Balcony and Terrace. Switch is used to operate the solenoid valve which is instructed by the web server in communication with the cloud data base. By physical verification and plant requirements a time interval of 4 min was set in the cloud data base. Internet of things (IOT) and cloud computing are two complementary technologies which were merged with the application specific hardware design enriched with smart sensors collectively provides the data which is stored in cloud. The data stored in the cloud database is accessed using the web services. Feedback system which is used to send and receive the data that can be used for the analysis of requirements.
\end{abstract}

Keywords: G-Switch, Solenoid, Drip irrigation, Web Server.

\section{INTRODUCTION}

City dwellers can now grow their own fresh supply of greens through Smart gardening. Within a limited amount of space, time, resources and challenging conditions of city, smart gardening makes modern farming easy. An automated watering solution allows the urban planters to thrive in the city setting. Time to time, watering the garden manually and standing for hours with water pipe can feel therapeutic. For people who have got green fingers and take plants as their extended family, smart garden helps in monitoring moisture and gives a feedback that helps to grow plants both in outdoor and indoor gardens. Water is essential for the proper growth of any plant. Without right soil moisture requirements growing plants is tedious. Manually doing the above is far beyond the guesswork, but smart soil

Revised Manuscript Received on April 13, 2020.

* Correspondence Author

Ms. K. Ojeswini Sesi Priya*, Student, B. Tech (ECE), GRIET Hyderabad.

Ms. P.V.S.S. Rashmika, Student, B. Tech (ECE), GRIET Hyderabad, India.

Mr. K. Jamal, Ph. D, GRIET Hyderabad, India.

Ms. R. Indu Sree, Student, B. Tech (ECE), GRIET Hyderabad

Ms. T.N.S Kruthika, Student, B. Tech (ECE), GRIET Hyderabad

(C) The Authors. Published by Blue Eyes Intelligence Engineering and Sciences Publication (BEIESP). This is an open access article under the CC BY-NC-ND license (http://creativecommons.org/licenses/by-nc-nd/4.0/)
Smart garden is a modular indoor planter system where we sensors analyse the data and is primary driver for an automated experience at home. have customized the layout based on the plants requirements. We have arranged and stacked the planters which is expandable in future. The bulk of smart indoor devices are app-based while the communication between them is cloud based.

The smart garden which includes:

- Plants with zone specific requirements

- $\quad$ Each zone with its unique irrigation supply

- A custom made board with a module to monitor the moisture level of the soil

- Powered wireless gateway to switch the output ' $O N$ ' and 'OFF' based on the user defined time slots.

All the above requirements are contained inside the zones of gardens to make it look smart. Our project contains a moisture sensor and machine learning gateway to send a reminder when plants need watering. It is useful when one is forgetful of your house garden. The module used has both analogue and digital readings. The analogue readings gives the variable resistance between the solenoids that allows to estimate the moisture content of the soil. Based on the calibrated digital outputs we simply 'on' or 'off' by using web services. Fig. 1 proposes the major drawbacks in implementation of smart gardening. Fig. 2 shows some important processes involved during smart gardening.

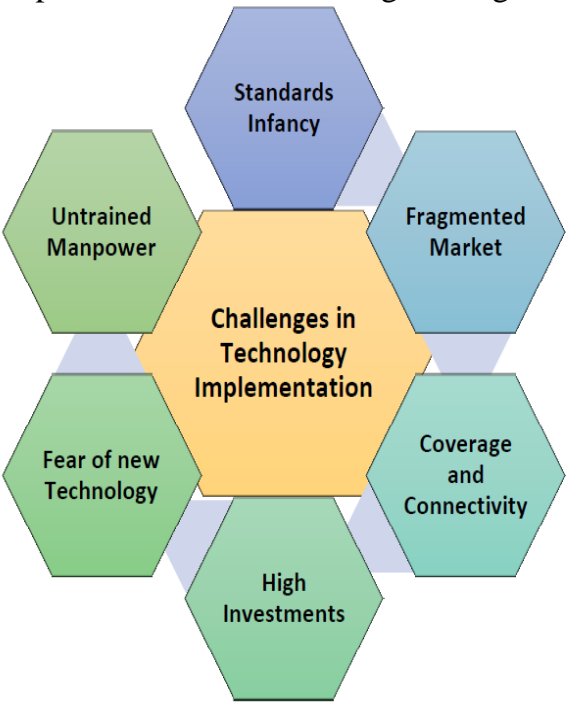

Fig. 1 Drawbacks in implementation of smart gardening

Published By:

Blue Eyes Intelligence Engineering DOI: $10.35940 /$ ijeat D8436.049420

Journal Website: www.ijeat.org

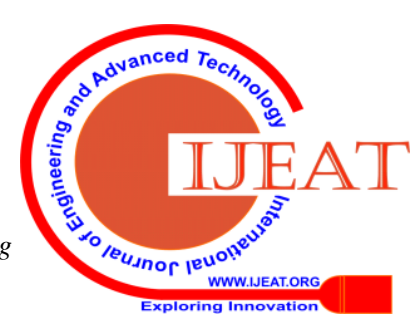

\& Sciences Publication

(C) Copyright: All rights reserved. 


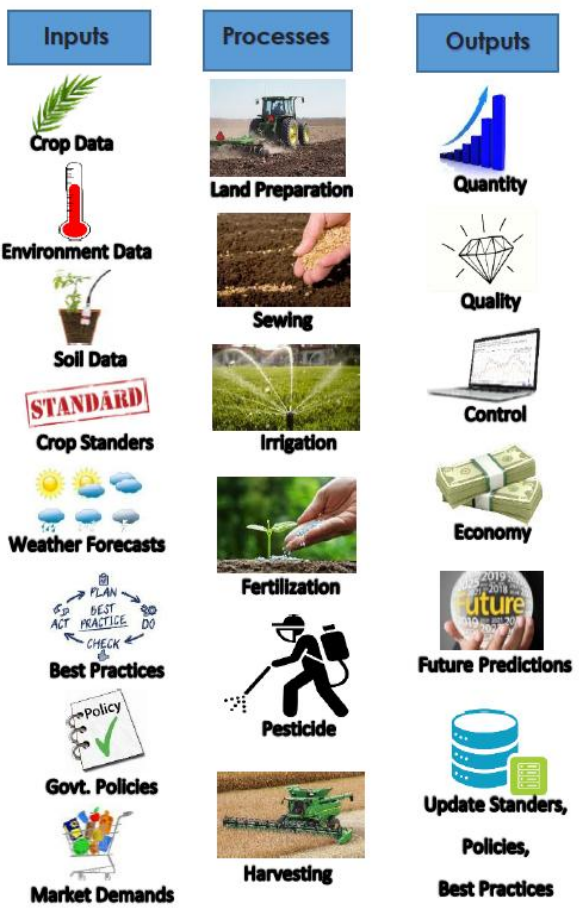

Fig. 2 Processes in smart gardening

\section{GOALS AND OBJECTIVES}

\section{A. Objectives:}

Our project is hence designed to reduce this pointless usage of water while gardening by providing automated water systems. The primary purpose of this project is to minimize the human effort in maintaining and watering plants since it is a tedious job and to upgrade the overall efficiency of the system without the human intervention. This way, it manages to perform efficient home irrigation, while it provides an efficient managing system. The building blocks of our project are web interfaces to define a garden and garden time slots. A garden with certain plants with multiple zones.

\section{B. Goals:}

- To fulfil the water requirements with no mechanical work

- Time to time watering of system

- User friendly control on watering system

- Choosing an appropriate plants and condition based on environment.

\section{LITERATURE REVIEW}

Burton et.al [1] developed smart gardening by employing IOT as a tool for prediction of real-time based nutrients available in plants. Disposable solid sheet IoT is used to analyse the real-time available soil based nitrates during irrigation and leach of the plants. By analyzing and measuring the concentration of nutrients in the soil they have determined the soil levels of letchate there controlling the $\mathrm{pH}$ and composition of ions in the soil the microbal properties were improved and more yield in the plant was observed. Garcia et.al [2] developed sensor-based irrigation system by incorporating IoT and WSN for determining the volume of water for supply including the quality and characteristics of soil and the condition of the weather. Flood, Spray, Drip and Nebulizer type of irrigation techniques with FCAP security system were employed for evaluating the parameters and finally concluded that nebulizer has given better results compared to other irrigation systems. Ayaz et.al [3] developed IoT based sensor incorporation with smart telecommunication techniques for agricultural needs and developed bug, twin, leaf, root, soil and environmental sensors for effective means of communication with farmers and thereby concluded that these sensors play a key role in developing the key parameters of the soil productivity like moisture $\mathrm{pH}$ etc. Biswat et.al [4] developed different platforms by integrating by employing cloud based computing which integrates thing speak, android and ardunio for achieving the goal by incorporating .Net application in houseplant watering and developed wireless frame network and concluded that AM2302 recorded better results compared to DHT11 and SHT71 in terms of cost, stability and accuracy etc. Anitha et.al [5] developed IoT base automatic type of soil moisture measurement monitoring system for raspberry plant and monitored the soil and weather conditions using API based frame type by incorporating the cloud computing and concluded that statistical sensors and machine learning improved the threshold value and yielded better grow in raspberry plant.

\section{PROPOSED METHODOLOGY}

The sketched architecture as shown in Fig. 3 is designed to reduce this pointless usage of water while gardening by providing automated water systems. The primary purpose of this architecture is to minimize the human effort in maintaining and watering plants since it is a tedious job and to upgrade the overall efficiency of the system without the human intervention. The building blocks in the present research work, are web interfaces to define a garden and garden time slots. A garden with certain plants with multiple zones.

\section{A. Block Diagram}

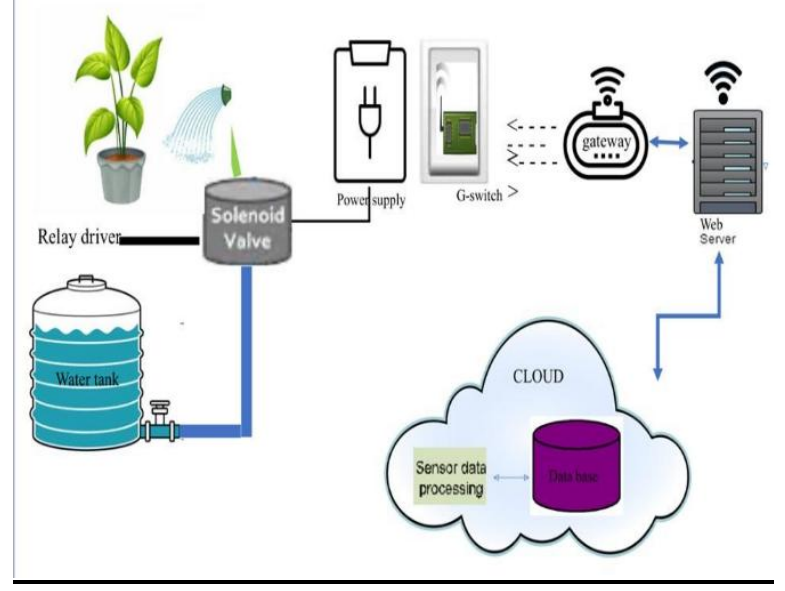

Fig. 3 Block diagram of automated watering system

The different zones categorized for research work is discussed below:

Zone - 1 (Patio)

The first and foremost zone in our garden is "Patio" as shown in Fig. 4.

Published By:

Blue Eyes Intelligence Engineering

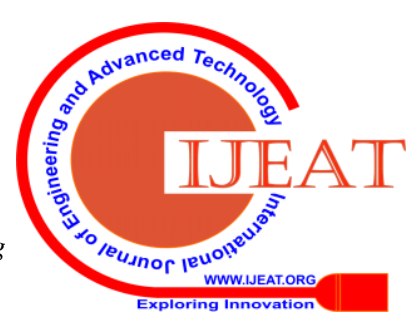


The front garden is the most beautiful part of the word "Patio" meaning "courtyard" which comes from Spanish. Patio is an outdoor space which is used to dine in the open sky. They are generally paved and is used in the recreation of the house. Patios can be paved with concrete, stone slabs, bricks, tile or cobbles, gravels. Thus, patio is referred to as an area outside house which has rooftop and is used for relaxing or eating in appropriate weather conditions. The patio is generally built in a way that it is straight beside the house and is directly built on ground. As the patio is built directly on ground, one need to choose a level floor to create a patio. While building a patio it is necessary to provide an easy access to kitchen. It consists of immense combinations of plants, flowers of different colours, their fragrance, sounds produced by birds and insects thereby soothing our mental stress and providing relaxation. Thus, one can make a colourful and beautiful garden in this zone by selecting exotic flowers. Plants like Anthurium, Asiatic lily, Gerbera are grown in this zone. In this zone we use shade loving plants. They add great colour to the garden. Installed dripping system is shown in Fig. 5.

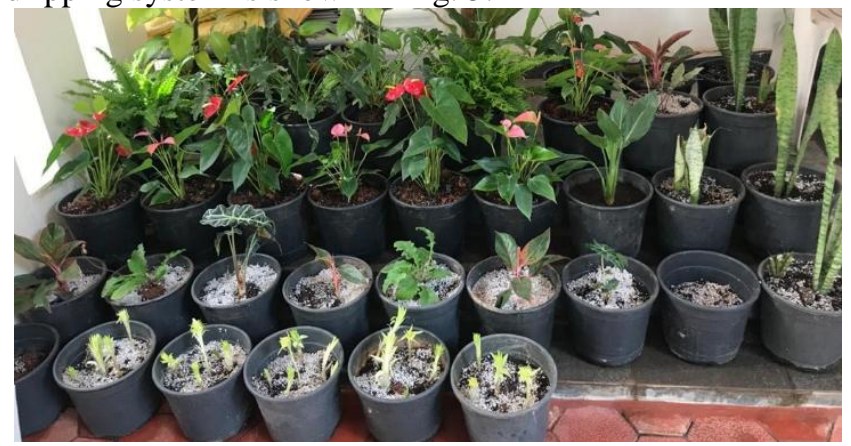

Fig. 4 Patio zone

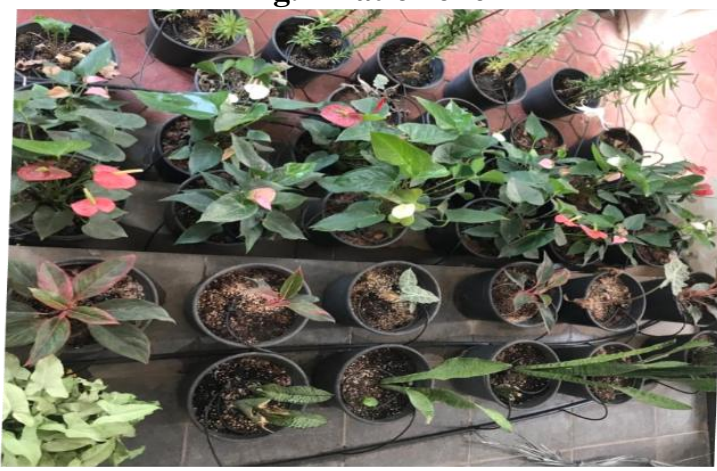

Fig. 5 Drip system installed at patio zone

\section{ZONE - 2 (BACKYARD)}

The second zone in our garden is "Backyard" with sprinkler and drip installed is shown in Fig. 6. It means a garden or yard at the backside of the house. Backyard farming refers to a process in which people living in typical areas convert a part of their property into small farms. "Backyard" means work is done at house and "farming" means we are using suitable and appropriate approaches in growing plants. Since, no chemicals are used it can be referred to as "Organic gardening". This approach is based on "permaculture" in which "nature" is used as a weapon to increase the yield of fruits, vegetables and flowers. Backyard gardening inspires you to take an interest of origin of your own food. It helps you to eat more fresh fruits and vegetables. Vegetables ripen in your garden have more nutrients compared to store-bought vegetables. Crops that are grown in this zone are tomatoes, brinjal, mangoes and many herbs like basil, cilantro, rosemary etc. Thus, one of the major benefits of this gardening is it lowers the grocery bills by growing crops in our garden and to reduce waste by composting items that are generally thrown out. The irrigation techniques used in this zone are dripping, sprinklers and misting. Misting device is a collection of misting nozzles which are mounted in a tube and pressurized to provide a fine water spray.

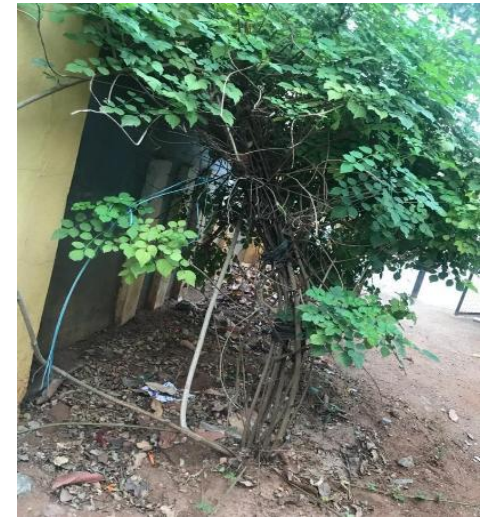

Fig. 6 Zone -2

\section{ZONE - 3 (BALCONY)}

The third zone in our garden is "Balcony" as shown in Fig. 7. Water connections and supply from the tank is shown in Fig. 9. The main purpose of this zone is to enable a smart garden in the balcony attached to a modern kitchen. Gardening may feel trickier for people living in apartments but is not necessarily. One can turn a small balcony into a lively place for birds, butterflies and themselves. Balcony here is converted into smart garden where we have indoor shaded plants (betel leaves, ferns), flowering plants, hanging pots placed in growbags and herbs which can be used for cooking purposes. Crops grown in this zone are leafy vegetables, tomatoes, herbs and money plants. The irrigation techniques used in this zone are dripping and hydroponics. In hydroponics water consumption will be less. The pump supplies the nutrient solution to the planters the excess solution is feed back to the planters forming a closed loop. Hydroponics will be the future of gardening and farming as shown in Fig. 9. Hydroponic gardening eliminates the use of herbicides and pesticides compared to traditional soil gardening. Vertical hydroponic systems provide an excellent option for gardeners lacking space by using PVC pipes as shown in Fig. 10.

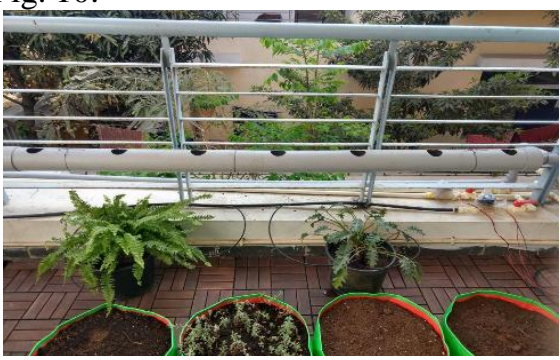

Fig. 7 Zone-3

Published By:

Blue Eyes Intelligence Engineering DOI: 10.35940/ijeat.D8436.049420

Journal Website: www.ijeat.org
\& Sciences Publication

(C) Copyright: All rights reserved.

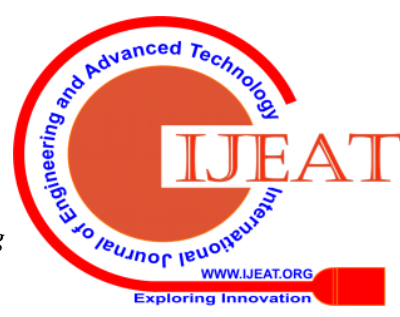




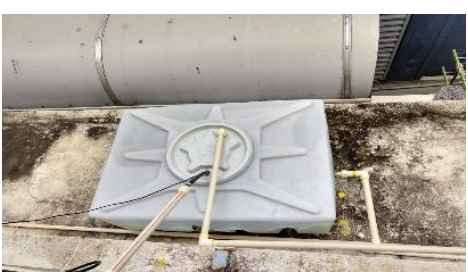

Fig. 8 Water supply form tank

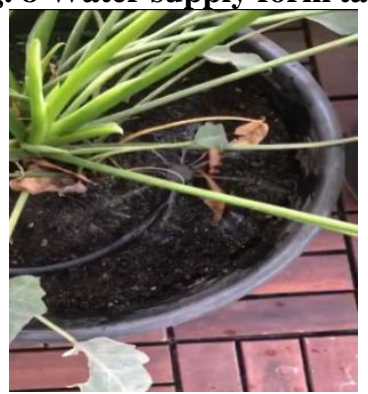

Fig. 9 Drip nozzle sprinkling on the plant

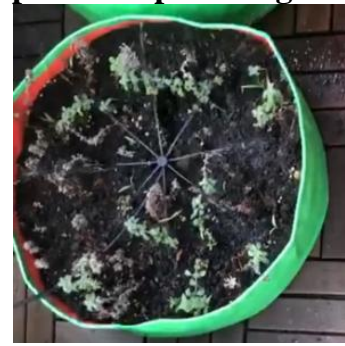

Fig. 10 Drip of water in to the plant

\section{ZONE - 4 (TERRACE)}

The fourth zone in our garden is "Terrace" as shown in Fig. 11. It is also referred to as "roof garden". It is the place where we get fresh air, water and sunlight. Terrace gardening provides opportunity for both sun loving and shade loving plants. This gardening doesn't require any additional space as it is grown on the roof of the house. Terrace gardening provides us fresh fruits and vegetables, it also reduces the pollution in the environment by increasing the oxygen levels in the atmosphere. Terrace gardening reduces the heat reflected off the roof in the summer. It can be used as recreational area. Roof gardening increases the amount of oxygen in air. Helps to reduce the soil erosion. Plants grown in this zone has ideal exposure to sunlight. Crops grown in this zone are mulberry mangoes, citrus fruits, water apple, wood apple. The irrigation techniques used in this zone are dripping as shown in Fig. 12. It has potential to save water and nutrients by allowing water to drip slowly to the roots of plants. Dripping system saves both time and effort. The garden requires only a few seconds to turn on and off the system by using a timer for watering the garden. Drip system works on low pressure unlike people plants also needs the nutrients in a balanced way as shown in Fig. 13.

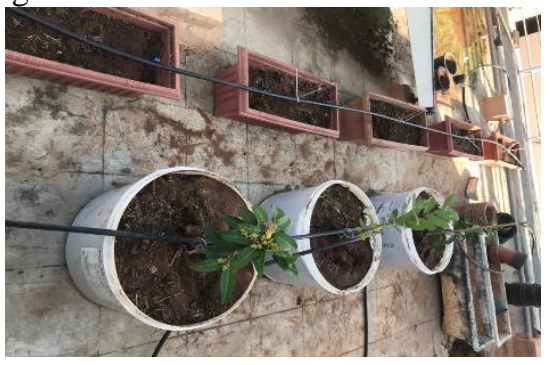

Fig. 11 Zone - 4

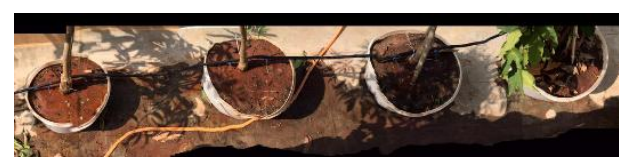

Fig. 12 Drip line for plants

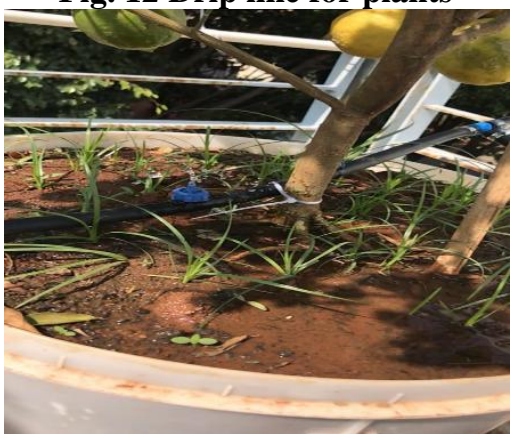

Fig. 13 Drip for each plant

\section{ZONE - 5 (FRONT YARD)}

The fifth zone in our garden is "Front yard" as shown in Fig. 14. Front yard forms centre of attraction to a house. The simplest facade can be made interesting. A well-maintained front yard can make an ordinary house to look better. Most of the plants grown in this zone are flowering plants as they seek the attention of the viewer and they are available here in different colours. We can make it more attractive by working with stones and pebbles. Plants grown in this zone are crotons, herbs, ferns, flowering plants like chrysanthemum, lilies, orchids and embryophytes. Plants are arranged according to the amount of sunlight they receive. The irrigation technique used in this zone is dripping. Also, since it is at the entrance of the house, it becomes significant to grow plants that flower throughout the year and attract the people attention as shown in Fig. 15. The water supply technique generally used in this zone is dripping. For small and delicate plants, we use a thin pipe and nozzle's at minimum distance required as shown in Fig. 16.

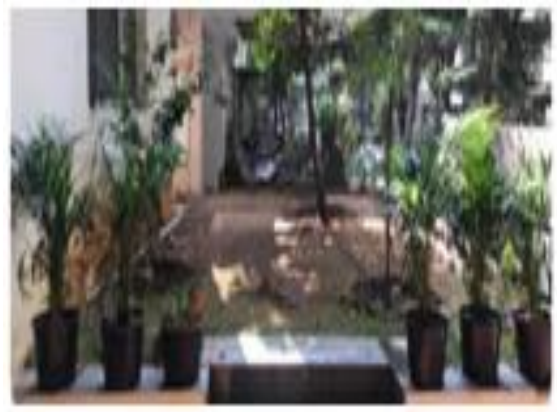

Fig. 14 Zone-5

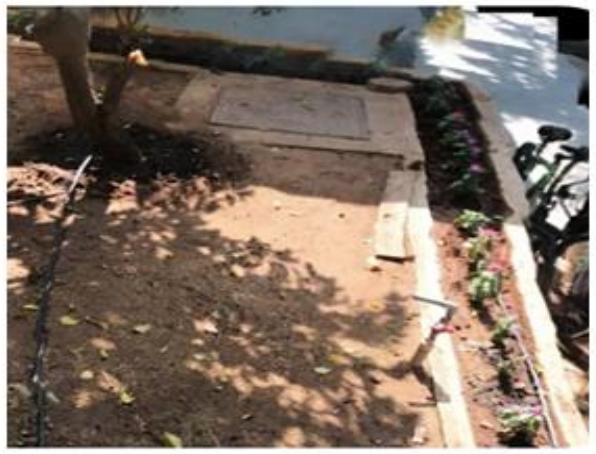

Fig. 15 Drip setup

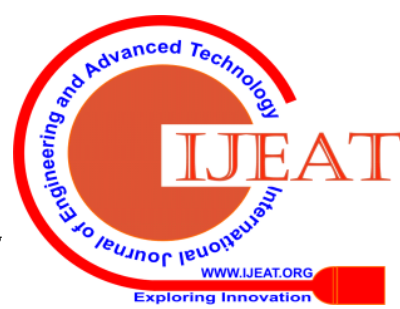




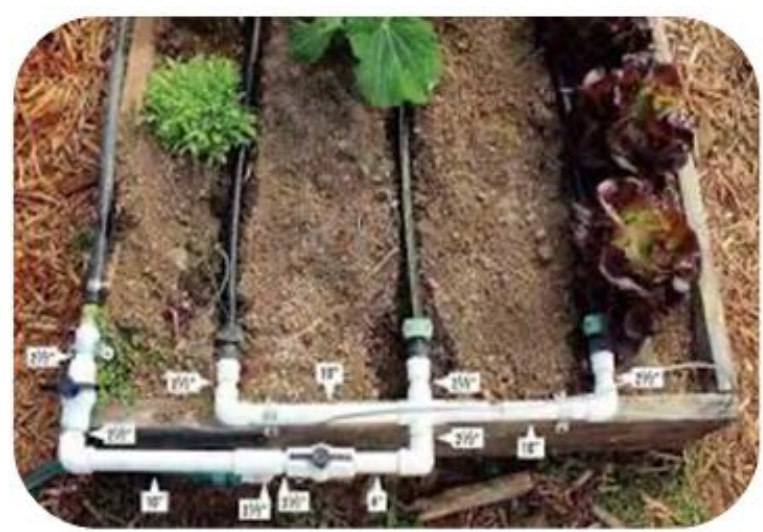

Fig. 16 Valves and nozzles arrangement

Dripping:

Drip irrigation is also known as "micro irrigation". This technique has an advantage to reduce the usage of water and to save nutrients by slowly dripping water to the plant roots which is done either from the surface of the soil or by concealing it within the soil. This is one of the most commonly used method of irrigation at present. This technique consists of pipes containing holes placed in rows besides the crops through which water is supplied to crops slowly. The main purpose of this method is to supply water to roots of plants thereby reducing the loss of evaporation. It can be performed using valves, tubes, pipes or emitters as shown in Fig. 17 and 18 respectively.
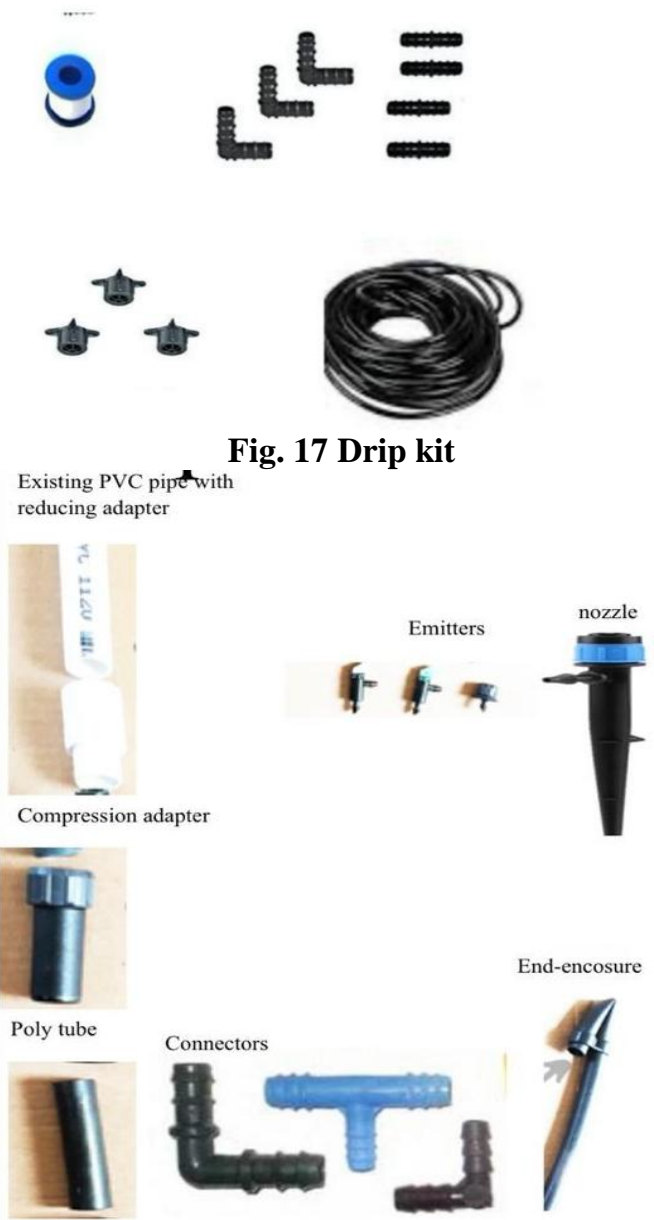

Fig. 18 Drip conversion kit

The drip nozzle as shown in Fig. 19, emitters are placed into the holes and these should be tightly closed and we should make sure that its air tight.

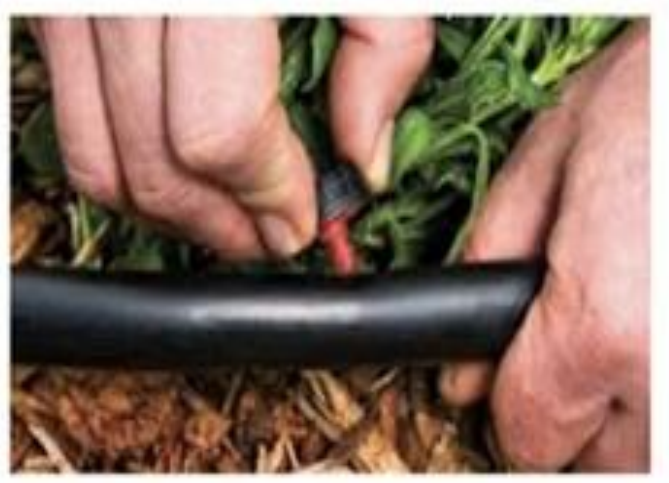

Fig. 19 Installation of drip nozzle into PVC pipe

Hydroponics:

The word "Hydroponics" comes from Greek word where "hydro" means water and "ponics" means labour. The main concept of hydroponics is growing plants without using soil. In this method, instead of using soil, plants are supplied with solution containing minerals and nutrients along with water for the growth of plants. This solution to exposed to the roots of the plants. Drilling of PVC for planting the plants is shown in Fig. 20. Plantation of trees in to the drilled holes is shown in Fig. 21.

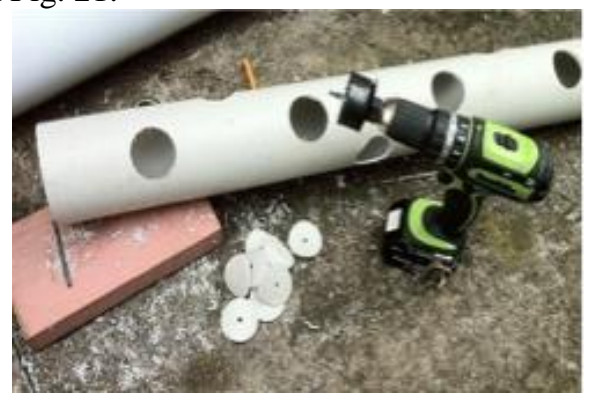

Fig. 20 Drilling of holes in the PVC pipe

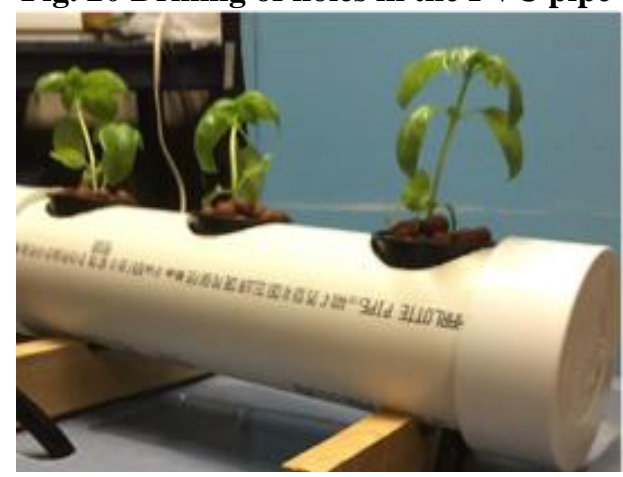

Fig. 21 Plantation of trees in to the drilled holes

\section{B. Algorithm}

Hardware and schematics provided we developed the switch firmware is shown in Fig. 22. Pictorial view of switch is shown in Fig. 23. Operation of switch is shown in Fig. 24. /*

* HTTP Client GET Request

* Copyright (c) 2018, circuits4you.com

* All rights reserved.

* https://circuits4you.com

* Connects to WiFi HotSpot. */ \#include <ESP8266WiFi.h> \#include $<$ WiFiClient.h $>$ \#include

$<$ ESP8266WebServer.h>

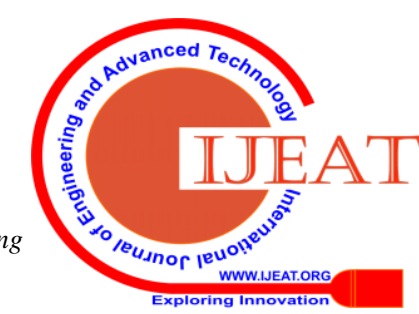


\#include <ESP8266HTTPClient.h>

/* Set these to your desired credentials. */

//const char *ssid = "B20DR24"; //ENTER YOUR WIFI SETTINGS

//const char *ssid = "IOT LAB"; //ENTER YOUR WIFI

SETTINGS

//const char *password = "Rabindranath@Tagore1234\#";

const char *ssid = "BOEING"; //ENTER YOUR WIFI

SETTINGS

const char *password = "foryoureyesonly";

//Web/Server address to read/write from

//const char *host = "175.101.12.206";

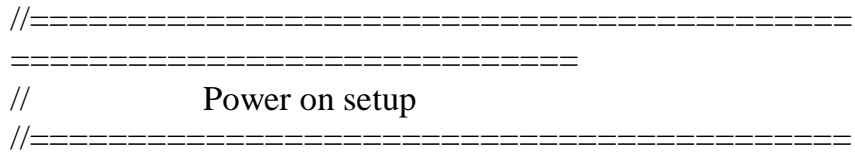

void $\operatorname{setup}()\{$

pinMode(D2,OUTPUT);

pinMode(LED_BUILTIN,OUTPUT);

delay(1000);

Serial.begin(115200);

WiFi.mode(WIFI_OFF); //Prevents reconnection issue

(taking too long to connect)

delay(1000);

WiFi.mode(WIFI_STA); //This line hides the viewing of ESP as wifi hotspot

WiFi.begin(ssid, password); //Connect to your WiFi router

Serial.println("'");

Serial.print("Connecting");

// Wait for connection

while (WiFi.status() != WL_CONNECTED) \{

delay(500);

Serial.print(".");

digitalWrite(LED_BUILTIN,!digitalRead(LED_BUILTIN))

\}

//If connection successful show IP address in serial monitor

Serial.println("'");

Serial.print("Connected to ");

Serial.println(ssid);

Serial.print("IP address: ");

Serial.println(WiFi.localIP()); //IP address assigned to your ESP

\}

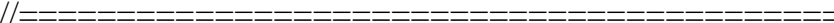

ニニニニニニニニニニニニニニニニニニニニニニニニニニニニニ

// Main Program Loop

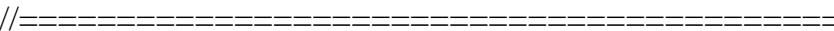

void loop() \{

HTTPClient http; //Declare object of class HTTPClient //GET Data

String

Link

"http://www.griet.in/gcap/iot/iotgetgarden.php?gardenid=09

\&format=json";

http.begin(Link); //Specify request destination

int httpCode = http.GET(); //Send the request

String payload $=$ http.getString ()$; \quad / /$ Get the response payload

Serial.println(httpCode); //Print HTTP return code
Serial.println(payload); //Print request response payload //Serial.println(payload.length());

Serial.println("==

$=======")$;

Serial.println(payload[1]);

//if(payload=="|"1|"')

if(payload[1]=='1')

digitalWrite(D2,HIGH);

else if (payload[1] $=={ }^{\prime}\left({ }^{\prime}\right)$

digitalWrite(D2,LOW);

http.end(); //Close connection

delay(5000); //GET Data at every 5 seconds \}

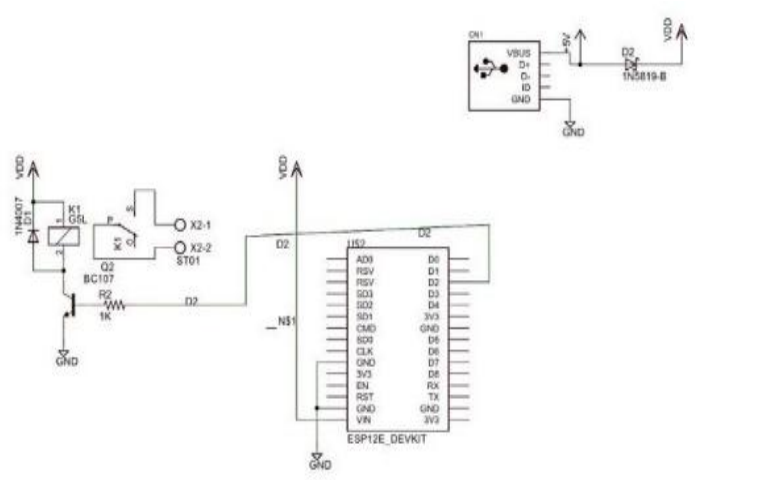

Fig. 22 Schematic diagram of switch

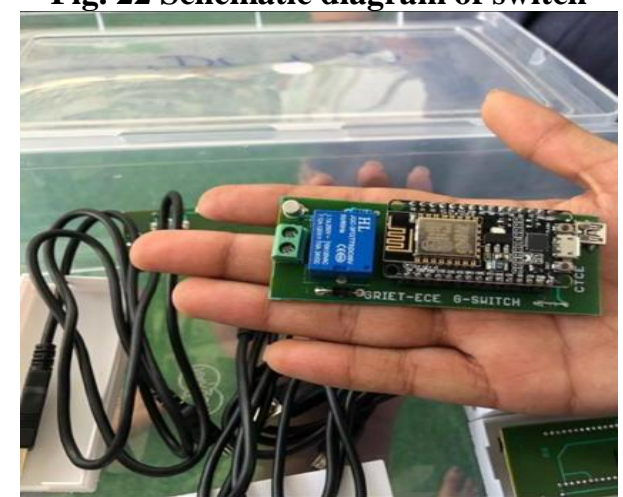

Fig. 23 Pictorial view of switch

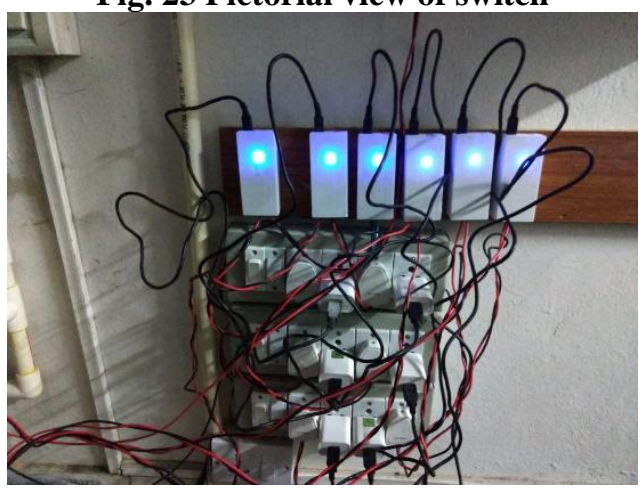

Fig. 24 Operation of switch

Switch contacts the cloud and has college developed web services. It gets switched ON or OFF information based on the timer settings. It operates the solenoid. If the switch is ON the solenoid is turned on and water goes to the drip pipes and is supplied to the plants. If the switch is turned OFF solenoid stops the water supply.Based on physical verification of plant requirements, the g- switch turns on with an interval due of $4 \mathrm{~min}$, At 8:00 AM and 17:00 PM switches on the water supply

Published By:

Blue Eyes Intelligence Engineering

DOI: 10.35940/ijeat.D8436.049420

Journal Website: www.ijeat.org

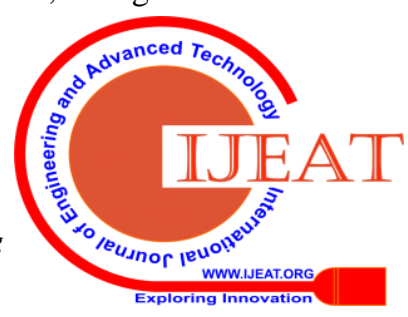


once to water the garden zones.

Next, at 8:03AM and 17:03 PM the supply is closed which is driven by algorithm. With the specified garden id (01 to 06) the slots starts and stops with the predefined status. During summer, the watering timings can be increased further as shown in Fig. 25.

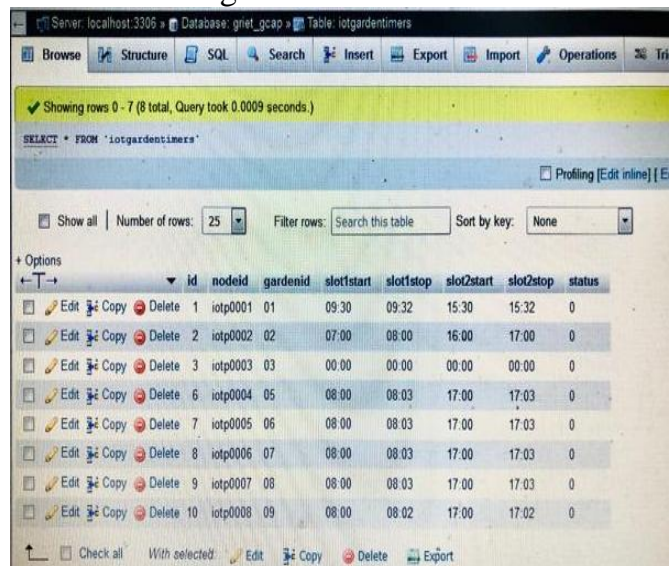

Fig. 25 Zone-wise timings

With the hardware connections ,the system enables people with little background in gardening to successfully grow vegetables in the most sustainable and resource-conserving way. Our project vision is to interface a growing garden by connecting to embedded board (g-switch) with the end goal that can measure humidity, moistness, and temperature and log that information (webservices). Thus, we need to set up The software side of the project mostly involving a server written for handling http requests from the embedded board.

The two web services used for communication gateway are "'iotgs3setsensordata.php?" and "iotgs3getsensordata.php?".

By using this set of web services and soil moisture values from the sensor, we can fill our table for calculating algorithm.

We represent all the collected values from the data base in the form of a database table. We designed our own web servers from the 'PHP' admin site.

- We need a web service to access the data that machine learning algorithm requires.

- We wrote a special URL for sending data “gcap.griet.in/iot/iotgs3.setsensordata.php?".

- The front-end part of the set sensor web service the requirement.

- In the same way we can get data from the web service,

URL “gcap.griet.in/iot/iotgs3getsensordata.php?".

- The main features of the get sensor is it shows a structured information after processing way which is presentable to the user.

We use the switch for the feedback for battery monitoring.

The positive end of the battery is tapped to the heltech module present in the smart soil sensor. This heltech module will be continuously monitoring the battery level and soil moisture content. The get sensor software mainly has a data structure which has three different main variables as shown in Fig. 24. The three variables are sensor id, battery level, soil moisture. has time slots mentioned for each zone based on

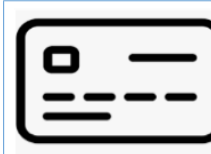

Senor ID

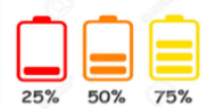

Battery Level

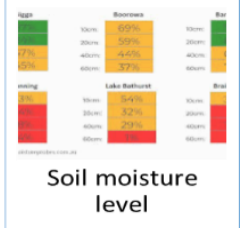

Fig. 26 Variables
In addition to this variables we can add few more variables like soil temperature, potential of Hydrogen $(\mathrm{pH})$, soil nutrients (Nitrogen, Phosphorous, Potassium). Agriculture information cloud is constructed with different resources to achieve dynamic distribution of resource and load balancing.

\section{FLOWCHART}

The flow of present research work, is pictorially represented in the Fig. 27. The steps involve in the flow chart are discussed below:

STEP 1: To arrange the smart sensor and the suitable irrigation techniques required in each zone depending on the plant needs.

STEP 2: Now, we need to ensure that the user defined time slots (i.e., the time slots we created for watering the plants) are activated in order to be watered at the specific time.

STEP 3: Then, it checks whether the time slots created match with any of the five zones of our project.

STEP 4: If the output of the above step is "yes" then the solenoid present is turned $\mathrm{ON}$ and the water is sent into the drip pipes and thus the plants of that specific zone are watered.

If the output is "no" then the process goes back to step 2.

STEP 5: In this step, the plants are watered according to the time slots provided by the user and then the status of each zone is updated. Here, we allotted two time slots of four minutes each.

Time slot 1: $8.00-8.03$

Time slot 2: $17.00-17.03$

These time slots are decided based upon the physical verification of the plants required.

These time slot durations can be further increased in summer.

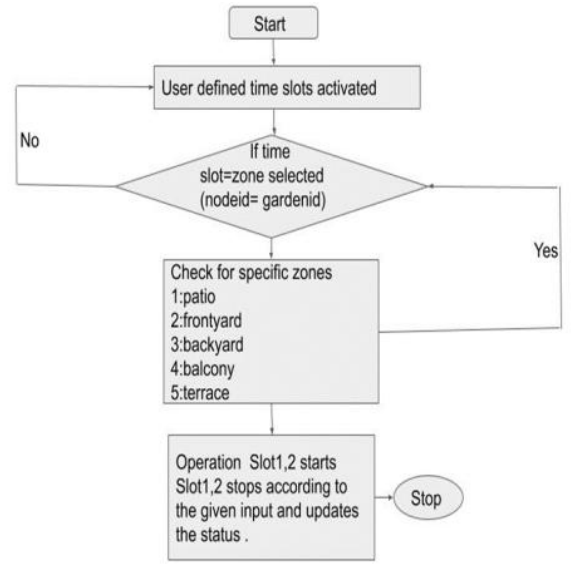

Fig. 27 Flowchart of the proposed architecture

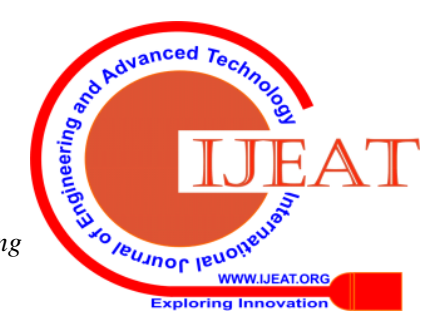




\section{RESULT ANALYSIS}

The data length of each data field should be alphanumeric with a preferred pre-fix. Each field length is set based on the requirement of each data field as shown in Fig. 28.

The values are taken in the form of "gs3001 03447 ".

Sensor id:(gs3001) It has a field length of 6 digits.

Battery level: ' 0 ' represents that the battery is OFF and ' 1 ' represents that the battery is $\mathrm{ON}$.

Soil moisture: It is displayed in 12-bit ADC form $\left(2^{\wedge} 12\right)$.

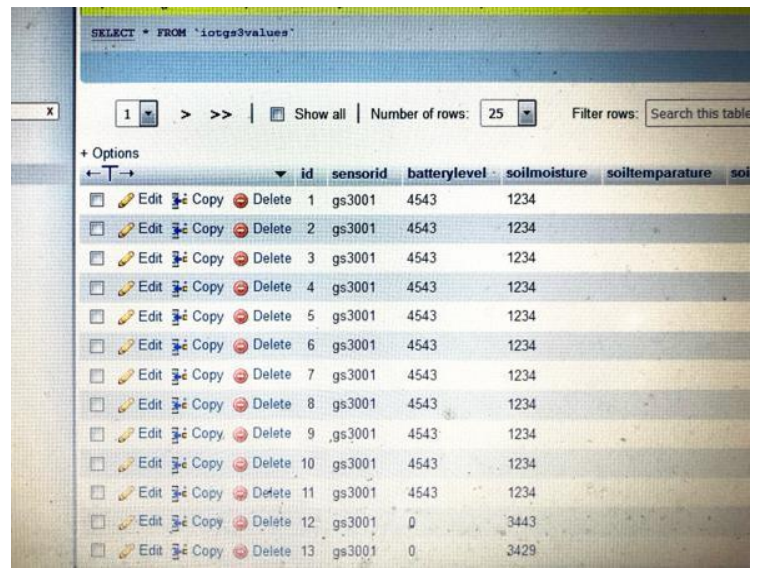

Fig. 28 Moisture level values

\section{CONCLUSIONS}

- ON and OFF of gardening water system was done according to the fixed clock timer settings in all the five zones.

- $\quad$ The soil parameters like moisture, rate of absorption of water, PH levels and salinity in the plants was controlled and improved growth in the plants mainly at Zone - 3 and Zone - 5 were observed compared to other zones.

- Drip irrigation technique is a suitable irrigation technique for maintaining good soil properties and plant growth.

\section{ACKNOWLEDGMENT}

The authors are thankful to Dr. N. Swetha HOD of ECE GRIET, Mr. K.N Balaji Kumar and Mr. A. Radhananda for guiding, encouragement and support for completion of the project.

\section{REFERENCES}

1. Burton. L, Dave. N, Fernandez. R.E, Jayachandran. K, Bhansali. S, “ Smart Gardening IoT Soil Sheets for Real-Time Nutrients", JTEC, Vol. 165, Issue - 8, 2018, pp. 3157-3162.

2. Laura. G, Lorena. P, Jimenez .M, Jaime. L, Lorenz. P, "IoT-Based Smart Irrigation Systems: An Overview on the Recent Trends on Sensors and IoT Systems for Irrigation in Precision Agriculture", MDPI, Vol. 20, pp. 1-48.

3. Ayaz. M, M.A Uddin, Z.S.A. Mansour, M. Aggoune, "Internet - of Things (IoT) based smart Agriculture: Towards Making the Fields Talk", IEEE, 2019, pp. 1-34.

4. Biswal. V, Singh, H.M, Jeberson. W, Dhar, A.S, "Greeves: A Smart Houseplant Watering and Monitoring System”, IJSETR, Vol. 4, Issue. 7, 2015, pp. 2499-2507.

5. Anitha. R, Suresh. D, Gnaneswar. P, Puneeth. M.M, "IoT Based Automatic Soil Moisture monitoring System using Raspberry PI", Vol. 9, Issue. 2, 2019, pp. 4375-4379.

\section{AUTHORS PROFILE}

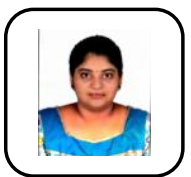

Ms. K. Ojeswini Sesi Priya is presently pursuing her B.Tech (ECE) in GRIET Hyderabad. Her areas of interests are VLSI and Embedded systems.

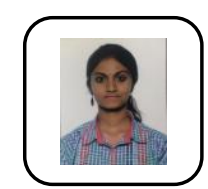

. P.V.S.S. Rashmika is presently pursuing her B.Tech (ECE) in GRIET Hyderabad. Her areas of interests are VLSI and Embedded systems.

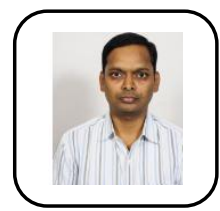

Mr. K. Jamal received his B.Tech Degree in Department of ECE from JNTU, Andhra Pradesh, India and M.Tech in VLSI Design from Bharath University, Tamil Nadu, India. He is pursuing Ph.D from GITAM University, Andhra Pradesh, India. He has about 15 years of experience in teaching. His areas of interest include VLSI and Embedded Systems. His research interests include VLSI and Embedded Systems. He has published more than 20 papers in reputed international journals and conferences.

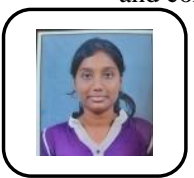

Ms. R. Indu Sree is presently pursuing her B.Tech (ECE) in GRIET Hyderabad. Her areas of interests are VLSI and Embedded systems.

Ms. T.N.S Kruthika is presently pursuing her B.Tech (ECE) in GRIET Hyderabad. Her areas of interests are VLSI and Embedded systems.

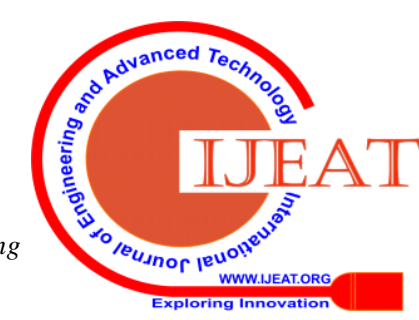

